54, 2, pp. 503-516, Warsaw 2016

DOI: $10.15632 /$ jtam-pl.54.2.503

\title{
ANALYSIS OF THE PROCESS OF WOOD PLASTICIZATION BY HOT ROLLING
}

\author{
Marian Dudziak, Ireneusz Malujda, Krzysztof Talaśka, \\ Tomasz Łodygowski, Wojciech Sumelka \\ Politechnika Poznańska \\ e-mail: marian.dudziak@put.poznan.pl; ireneusz.malujda@put.poznan.pl; krzysztof.talaska@put.poznan.pl; \\ tomasz.lodygowski@put.poznan.pl; wojciech.sumelka@put.poznan.pl
}

\begin{abstract}
In this research, a mathematical model is derived to enable analytical determination of effective ultimate forces in the process of plasticization of the surface layer of wood. The experimentally determined thermo-mechanical properties of the material subjected to the process of plasticization are used in defining the structure of the model. The analysis of plastic strain in the layer in consideration is based on a generalised model of an ideally rigid-plastic medium, including certain modifications. Considering the anisotropic properties of wood, the Azzi-Tsai-Hill (ATH) strength criterion is applied which takes into account variation in the response of the loaded material depending on the direction. The article presents also results of FEM analysis of the same process of hot rolling of wood.
\end{abstract}

Keywords: yield point, temperature, moisture content, porosity, orthotropy

\section{Properties of porous anisotropic natural polymers}

The focus is on designing machines and devices of newly developed techniques for modification of the internal structure and surface characteristics of products made of various engineered materials. These materials include wood, which is considered the oldest structural material, through generally used metals to the cutting edge composites. The inspiration to undertake this research are the machines designed to improve properties of natural wood veneered furniture components by application of hot rolling technique. Wood has been used to analyse the complex process of plasticisation of superficial layers of such materials with the objective to improve their quality as well as their strength and functional performance.

The efficiency of plasticisation and densification of such materials depends on the desired ultimate load values (Ashby and Jones, 1996). Hence, an extensive testing program has been carried out to determine mechanical properties of wood and their dependence on temperature and moisture content. The results were used to set up constitutive equations of plasticity and to build models describing these processes. This was the basis to determine the effective ultimate load values used to define the machine design criteria (Mackenzie-Helnwein et al., 2005; Malujda, 2006).

Properties of natural polymers are defined by specific and unique characteristics of the plant tissue of which they are made (Forest Products Laboratory, 1999; Kokociński, 2004). Some of them may be determined with organoleptic methods, others require highly specialised test apparatus to measure often mutually dependent physical quantities (Malujda and Marlewski, 2011). The values depend on several factors and phenomena which occur inside these materials exposed simultaneously to mechanical and thermal loading. Considering the number and complexity of characteristics of natural polymers such as wood, for the sake of clarity, a few important groups of properties and physical quantities have been identified, as schematically illustrated in Fig. 1. 


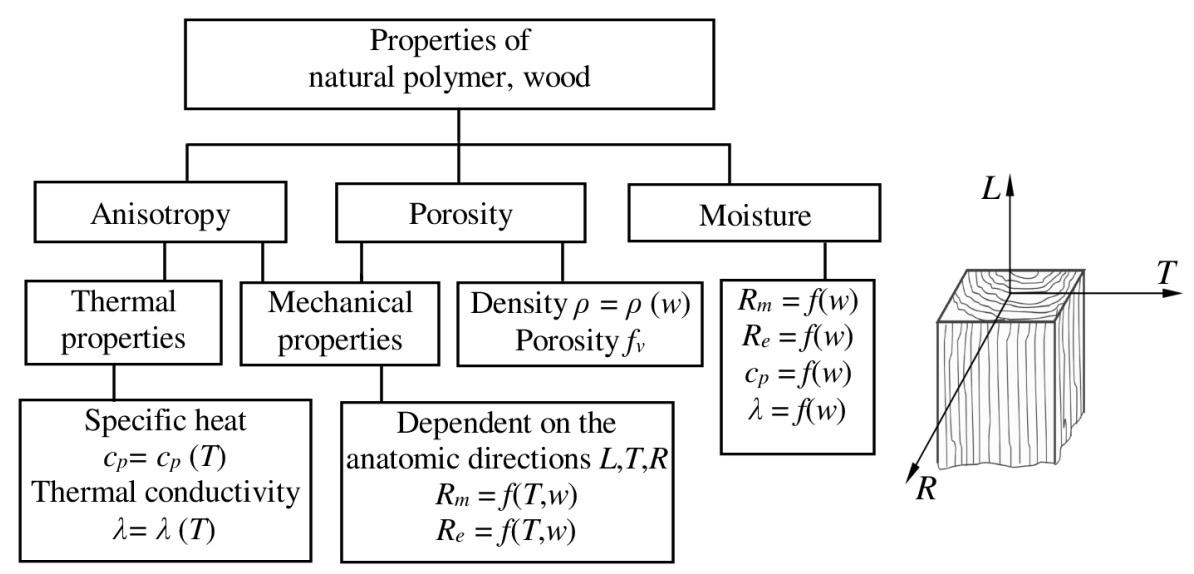

Fig. 1. The main thermo-mechanical properties of wood dependent on temperature and moisture content. $R_{m}$ is the ultimate strength and $R_{e}$ is the yield point, both in the three orthotropic directions: longitudinal $L$, tangential $T$ and radial $R$

There is a number of important complex biochemical phenomena involved in plasticization processes highly relevant to the desired modification of geometrical parameters of their surfaces and internal structures. These phenomena have not been analysed in detail, as this would exceed the scope of this study. However, it can be assumed that the effect of these phenomena on the thermo-mechanical properties is reflected in the material functions determined experimentally through tests carried out on a macroscopic scale (Sumelka et al., 2013).

The structural component of wood is cellulose, and it is the specific anatomical structure of cellulose that is responsible for the completely different structure and appearance of wood depending on the cutting direction. Skeleton-forming substances are based on cellulose and owe it its strength.

\section{Experimental motivation}

\subsection{Compression test}

The test specimens were subjected to compression load in the direction parallel to the grain and two perpendicular directions: tangential and radial. The specimens were made of beech wood (Fagus silvatica). The dimensions of test specimens are presented in Fig. 2. Fig. 3 shows the annual growth rings. The tests specimens were produced in sufficient number for the planned tests.

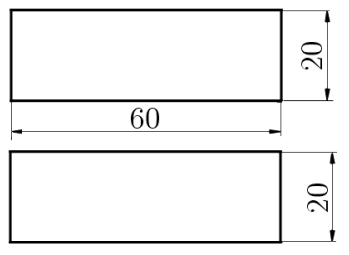

Fig. 2. Dimensions of the compression test specimen

The specimens were made of selected wood logs to obtain representative and reproducible results of testing as per Polish Standard PN-81/D-04107 (Kokociński, 2004). Specimens including structural features such as snags were rejected.

The specimens were compressed in the respective directions $(L, T, R)$ and the output results enabled relating the determined strength to temperature and moisture gradients. The tests were carried out at three temperatures: $20^{\circ} \mathrm{C}, 50^{\circ} \mathrm{C}, 80^{\circ} \mathrm{C}$ and three moisture contents: $9 \%, 18 \%$ and $27 \%$. The highest test temperature was $80^{\circ} \mathrm{C}$ because above that point chemical reactions 

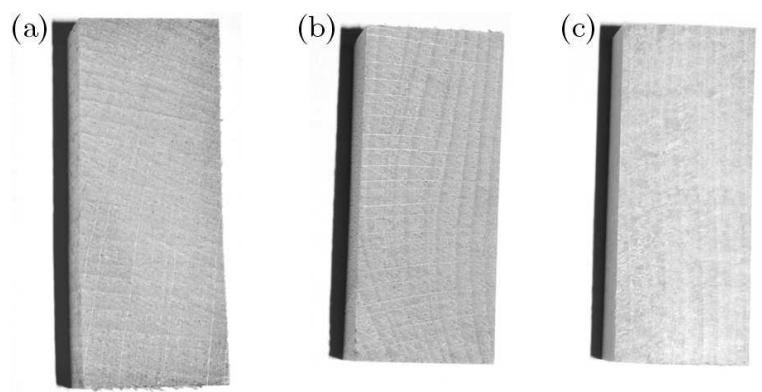

Fig. 3. Specimens: (a) radial direction, (b) tangential direction, (c) longitudinal direction

take place in beech wood, which brings unrecoverable changes in the composition and structure of wood. The moisture content was limited to $27 \%$, which in the case of wood is the practical limit for absorption of moisture from air. The testing program for one fibre direction is presented in Table 1.

Table 1. Testing program for one fibre direction

\begin{tabular}{|l|c|c|c|c|}
\hline \multicolumn{2}{|c|}{} & \multicolumn{3}{|c|}{ Temperature } \\
\cline { 3 - 5 } \multicolumn{2}{|c|}{} & $20^{\circ} \mathrm{C}$ & $50^{\circ} \mathrm{C}$ & $80^{\circ} \mathrm{C}$ \\
\hline \hline \multirow{2}{*}{$\begin{array}{l}\text { Percent } \\
\text { moisture }\end{array}$} & $9 \%$ & 3 & 3 & 3 \\
\cline { 2 - 5 } & $18 \%$ & 3 & 3 & 3 \\
\cline { 2 - 5 } & $27 \%$ & 3 & 3 & 3 \\
\hline
\end{tabular}

Before the test, the specimens were conditioned in a climatic chamber (Fig. 4b) to attain the equilibrium moisture content. After subsequent storage in ambient conditions at the laboratory, the moisture content of specimens was $9 \%$. The threshold values of $18 \%$ and $27 \%$ were achieved by placing the specimens in the desiccator above the saturated solution of $\mathrm{NaCl}$ and water respectively (Fig. 4a). The moisture content was checked by weighing of samples during conditioning until the desired value was obtained. The percent moisture at the point when the sample weight has stabilised is called the saturation moisture content. The weight was checked on a moisture balance with $0.001 \mathrm{~g}$ accuracy. Before each test, specimens of a specific percent moisture were heated up to the specified test temperature. The compression tests were carried out using a strength tester with $50 \mathrm{kN}$ load cell and MTS mechanical extensometer resistant to high temperature and moisture. The strength tester was integrated with the climatic chamber placed within the MTS working space to maintain the specified ambient conditions. The strength tester incorporating the climatic chamber is presented in Figs. 5 and 6.
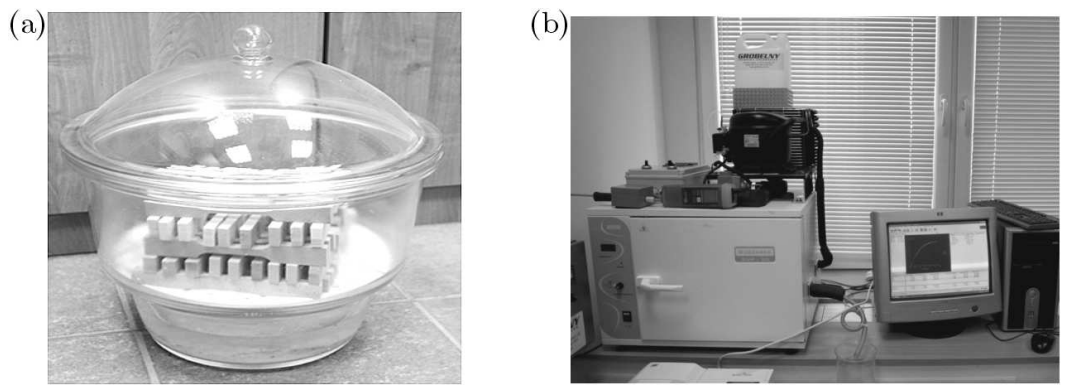

Fig. 4. (a) Desiccator with specimens placed inside, (b) stationary climatic chamber

The stress-strain curves were obtained for each compression test on the basis of extensometer displacement. The cross-sectional area of the specimen was determined before the test. The other input parameters, namely temperature and percent moisture, were measured right after the test. 


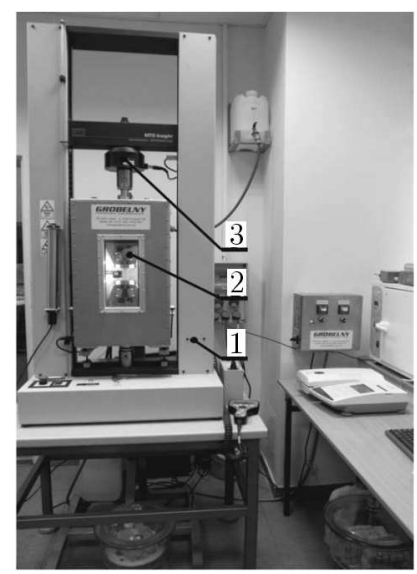

Fig. 5. MTS strength tester incorporating climate chamber 1 - strength tester, 2 - climate chamber, 3 - load cell (measuring the applied force)

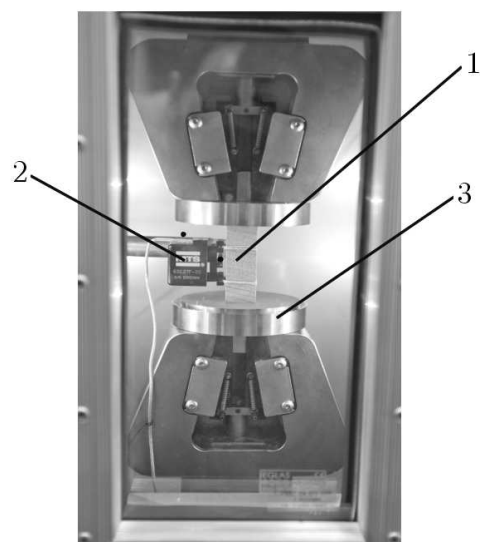

Fig. 6. Climatic chamber with holding jaws assembly designed for compression test: 1 - specimen placed between holding jaws, 2 - extensometer, 3 - force/ specimen alignment fixture to ensure that the force is applied perpendicular to the specimen cross-section

An example of a typical curve obtained from a compression test carried out on a specimen of beech wood in the tangential direction is presented in Fig. 7.

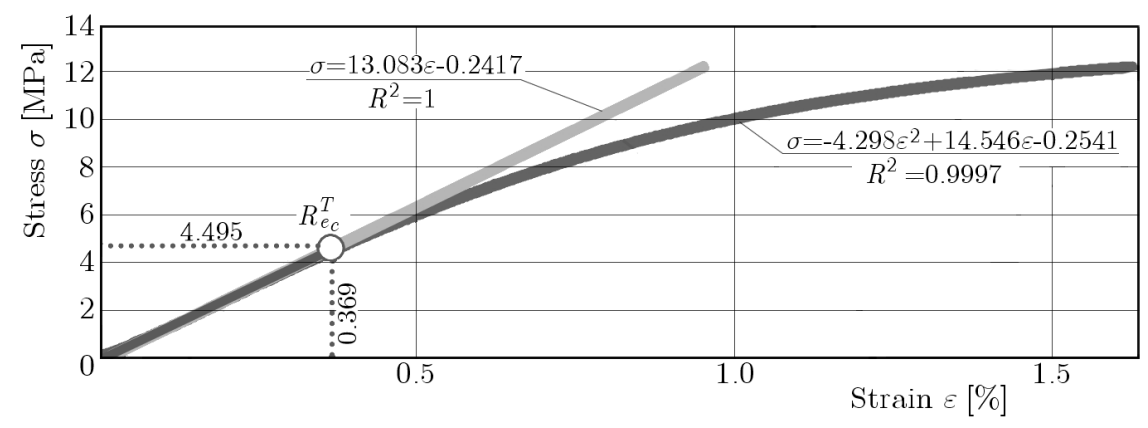

Fig. 7. The stress-strain curve for beech compressed in the tangential direction

The yield point values $R_{e}$ in the respective orthotropic directions $L, T, R$ were taken as the wood strength criterion used to set up constitutive equations describing the plasticization model of wood. For the compression test, those parameters were designated $R^{L} e_{c}, R^{R} e_{c}, R_{e_{c}}^{T}$, respectively. Their values were determined by the point where the tangent "departs" from the curve by more than $1 \%$ of the ultimate strength value. This point, in turn, was determined by 
solving a system of equations comprising an equation of a straight line tangent to the stress-strain curve in tension and an equation of the actual stress-strain curve in compression (Fig. 7).

The results of each test type were recorded in single test record sheets and test logs which included all the relevant strength test information. Table 2 presents an example of a single test record sheet from a compression test carried out on a beech wood specimen with $9 \%$ moisture at $20^{\circ} \mathrm{C}$. The test $\operatorname{logs}$ include the results obtained for the whole test series and accompany the respective test descriptions. An example of such a test log is presented in Table 3.

Table 2. Single test record sheet (compression of beech in the tangential direction, $9 \%$ moisture, $20^{\circ} \mathrm{C}$

\begin{tabular}{|l|c|l|}
\hline Wood variety & beech & \\
\hline Direction & tangential & \\
\hline Moisture content [\%] & 9 & \\
\hline Temperature $\left.{ }^{\text {circ }} \mathrm{C}\right]$ & 20 & \\
\hline Cross-section area $\left[\mathrm{mm}^{2}\right]$ & 402 & \\
\hline Young's modulus $E[\mathrm{MPa}]$ & 1282.857 & \\
\hline Breaking force [M] & 4894.27 & \\
\hline Ultimate strength $R_{c}^{T}[\mathrm{MPa}]$ & 12.175 & Test No. 1 \\
\hline Shortening at $R_{c}^{T}[\mathrm{~mm}]$ & 0.407 & \\
\hline Strain at $R_{c}^{T}$ & 0.016 & \\
\hline Yield point $R_{e_{c}}^{T}[\mathrm{MPa}]$ & 4.495 & \\
\hline Shortening at $R_{e_{c}}^{T}[\mathrm{~mm}]$ & 0.09225 & \\
\hline Strain at $R_{e_{c}}^{T}$ & 0.00369 & \\
\hline$R_{e_{c}}^{T} / R_{c}^{T}$ & 0.369 & \\
\hline Gauge length $l_{0}[\mathrm{~mm}]$ & 25 & \\
\hline
\end{tabular}

Table 3. One series of tests: beech - tangential direction

\begin{tabular}{|c|c|c|c|c|}
\hline & \multicolumn{3}{|c|}{ Test No. } & \multirow[b]{2}{*}{ avg. } \\
\hline & 1 & 2 & 3 & \\
\hline Wood variety & \multicolumn{4}{|c|}{ beech } \\
\hline Direction & \multicolumn{4}{|c|}{ tangential } \\
\hline Moisture content [\%] & \multicolumn{4}{|c|}{9} \\
\hline Temperature $\left[{ }^{\circ} \mathrm{C}\right]$ & \multicolumn{4}{|c|}{20} \\
\hline Cross-section area $\left[\mathrm{mm}^{2}\right]$ & 402 & 406 & 404 & 404 \\
\hline Young's modulus $E[\mathrm{MPa}]$ & 1282.857 & 1244.392 & 1267.786 & 1265.01 \\
\hline Breaking force $[\mathrm{N}]$ & 4894.27 & 5309.5 & 5239.05 & 5147.60 \\
\hline Ultimate strength $R_{c}^{T}[\mathrm{MPa}]$ & 12.175 & 13.078 & 12.969 & 12.7406 \\
\hline Shortening at $R_{c}^{T}[\mathrm{~mm}]$ & 0.407 & 0.565 & 0.475 & 0.48233 \\
\hline Strain at $R_{c}^{T}$ & 0.016 & 0.023 & 0.019 & 0.01929 \\
\hline Yield point $R_{e_{c}}^{T}[\mathrm{MPa}]$ & 4.495 & 3.541 & 4.21 & 4.082 \\
\hline Shortening at $R_{e_{c}}^{T}[\mathrm{~mm}]$ & 0.09225 & 0.073 & 0.08675 & 0.084 \\
\hline Strain at $R_{e_{c}}^{T}$ & 0.00369 & 0.00292 & 0.00347 & 0.00336 \\
\hline$R_{e_{c}}^{T} / R_{c}^{T}$ & 0.369 & 0.271 & 0.325 & 0.32152 \\
\hline
\end{tabular}

Having all the results, it was possible to define the relation between strength and temperature for the respective moisture content levels.

An example of the test results is presented in form of curves in Fig. 8. They relate the yield point $R_{e}$ to the effect of temperature for three different moisture content levels in the tangential direction. 


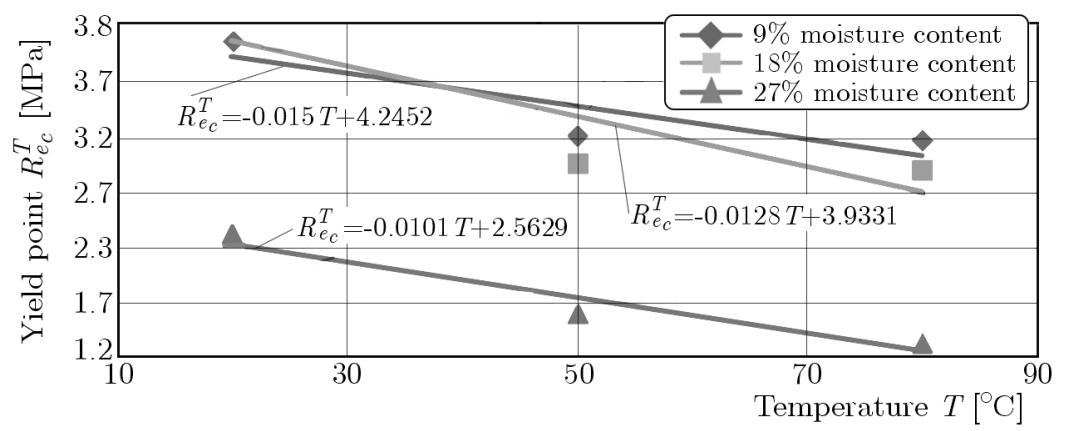

Fig. 8. Yield point $R_{e_{c}}^{T}$ vs. temperature $T$ for different moisture content levels (beech wood, tangential direction)

\subsection{Experimental determination of thermal conductivity}

The thermal tester used in the determination of the thermal conductivity of wood was designed specifically for testing materials of low thermal conductivity (Fig. 9a). As the first step, specimens of the same density and thickness were prepared. The test set-up components were aligned coaxially and then load was applied to the top of the heat sink. Then the whole set-up was thermally isolated and the remaining parts, namely temperature sensors, power supply unit and the measuring device were connected. The system was energised and the heat sink switched on. Measurements were taken upon reaching the test temperature and thermal equilibrium.

The measurements were carried out on beech wood (Fig. 9b) in the three directions in relation to the grain: $L, T, R$ (longitudinal, tangential and radial) at test temperatures of 40,60,80, $100,120,140$ and $150^{\circ} \mathrm{C}$ to obtain arithmetic average of five measurement results for each test point.
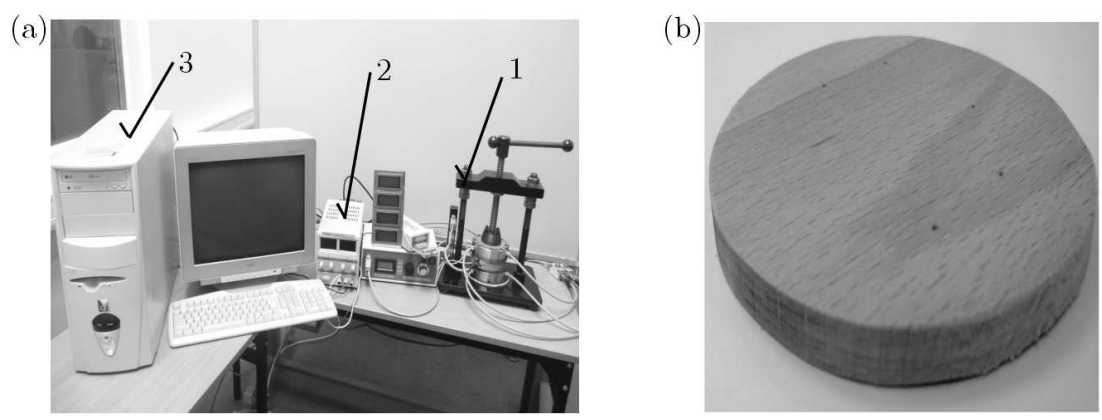

Fig. 9. (a) Experimental set-up for measuring thermal conductivity: 1 - thermal conductivity tester, 2 - amplifier, 3 - recording computer; (b) specimens of beech wood used for thermal conductivity measurement tests

The measurement results for beech wood were used to derive the curves (Fig. 10) relating the thermal conductivity coefficient $\lambda$ to temperature for the three directions in relation to the grain: $L, T, R$.

The relationship between the thermal conductivity and temperature is described with application of an arctan approximation model $\lambda_{\text {arctan }}$, specially developed for this purpose by the authors. This description is consistent with the approximation methods developed by several researchers working in different research centres (Harada et al., 1998; Gu and Zink-Sharp, 2005; Yang, 2001). Malujda and Marlewski (2011) demonstrated that the arctan approximation model provided more accurate approximation that the methods proposed by other researchers. 


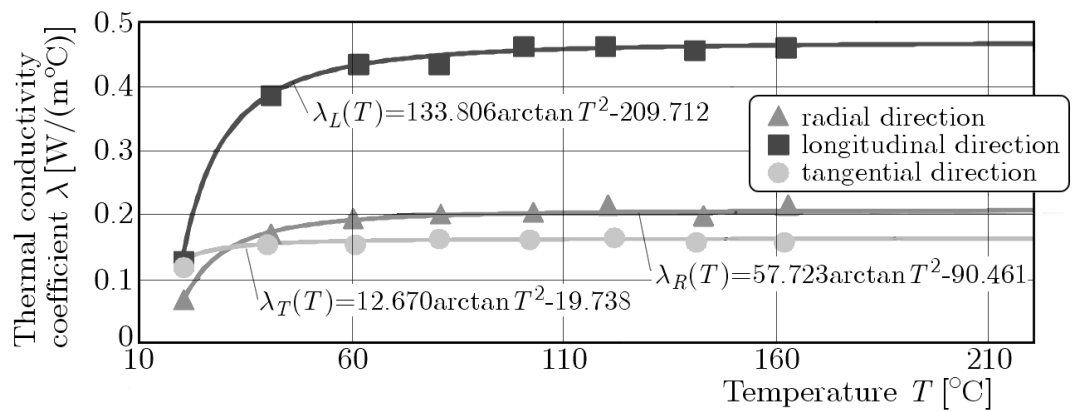

Fig. 10. Thermal conductivity vs. temperature for different fibre directions, approximation with the arctan model

\section{Analysis of plasticization of an anisotropic material}

In anisotropic materials, specific directions can be found in which plastic properties reach the extreme values. If these directions are oriented orthogonally one to another, we call it orthotropy, and the material with such characteristics is referred to as an orthotropic material (German, 2001). Wood is an example of such an orthotropic material.

The problem of defining the yield criterion of the surface layer of wood is approached as a two-dimensional problem (Fig. 11).

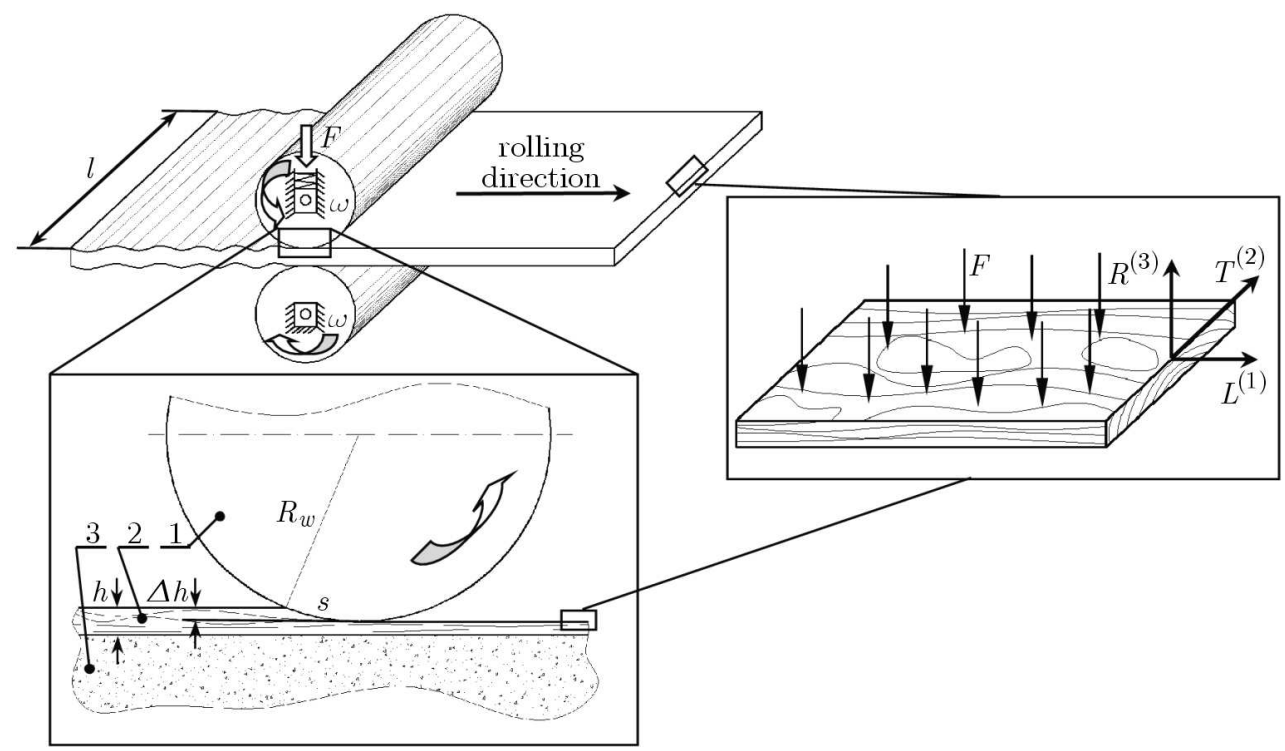

Fig. 11. Treatment to improve properties of the surface layer of the natural material by hot rolling: 1 - adjustable upper roller, 2 - layer of wood, 3 - chipboard, $R_{w}$ - roller radius, $s$ - roller/material contact length, $h$ - depth of the layer of wood, $l$ - board width, $\Delta h$-compression degree, directions: $L^{(1)}$ - longitudinal, $T^{(2)}$ - tangential, $R^{(3)}$ - radial

Let us use the anisotropic yield criterion of Azzi-Tsai-Hill (ATH) to analyse the ultimate stress-strain state of the analysed layer of wood, which considers its multi-directional reactions resulting from the components of the complex stress state. Hill (1956) generalized the HMH yield criterion to make it hold true for orthotropic materials. Wood is a natural polymer for which the reference system of co-ordinates can be set up so that the directions of axes coincide with the orthotropic directions $L, T, R$ (Fig. 11). Having taken this assumption, the yield criterion may be represented by

$$
\begin{aligned}
& (M+N) \sigma_{11}^{2}+(L+N) \sigma_{22}^{2}+(L+M) \sigma_{33}^{2}-2 N \sigma_{11} \sigma_{22}-2 M \sigma_{11} \sigma_{33} \\
& \quad-2 L \sigma_{22} \sigma_{33}+2 P \sigma_{23}^{2}+2 Q \sigma_{31}^{2}+2 R \sigma_{12}^{2}=1
\end{aligned}
$$


where $L, M, N$ are the proportional limits with the values depending on the orthotropic direction and $P, Q, R$ are the respective shear strength proportional limits.

The yield criterion formulated in this way is the strength criterion of an anisotropic material, and the critical strength is reached at the proportional limit. It is a characteristic feature of brittle materials, such as wood, for which these limits coincide with the yield and elasticity limits, and this has been confirmed by the results of experimental research.

The process of plasticization of natural materials having such complex properties as, for example, wood has not yet been described by non-linear models. Thus, the engineers cannot use a mathematical model whose structure is built of complex engineering constants, typical for natural polymers.

Now, let us take the process of hot rolling of wood (Fig. 11) and try to derive constitutive relations for natural materials by analytical method, assuming applicability of the theory of plasticity taking into account the plastic compressibility mechanism and allowing for the effect of heat and moisture (Bordia et al., 2006; Fujii et al., 2003; Malujda, 2006; Müllner et al., 2004; Nairn, 2005).

The key parameter for the modelling of the process in consideration is the ultimate stress corresponding to the lower limit of statically determined strength of the layer subjected to loading (Ashby and Jones, 1996). At this point, having in hand the mathematical model, we shall try to determine the ultimate load resulting in plasticization of the material. The value of this load is of primary importance to the efficiency of the analysed process.

The establishing of a model can be defined as the identification of the process occurring in the material. Therefore, it is necessary to carry out in-depth analysis of these elements of the model which are critical to obtaining a satisfactory solution thereof. In the case of wood, these are: complex thermo-mechanical properties, porosity and process parameters including in particular the ultimate force $F$ which depends on temperature and process duration (Malujda, 2006). Wood is a highly porous material and, for this reason, the ultimate stress depends not only on the second but also on the first invariant of the stress tensor. This effect must be considered in the final form of the yield criterion, similarly to the effect of direction in relation to the grain (Tsai and Wu, 1971). For this reason, the Huber von Mises-Hencky yield criterion for isotropic materials was used (German, 2001; Hill, 1956; Malujda and Talaśka, 2010), generalized by Azzi-Tsai-Hill (ATH) to hold true for anisotropic materials.

Scalar functions of porosity, temperature and moisture are then fitted into this yield criterion formula, generalised to hold true for anisotropic materials. Subsequent analyses are carried out for the assumed physical model of the unsupported rigid-plastic medium.

Now, let us formulate the general yield criterion expressing the yield criterion for an anisotropic and porous material allowing for the effect of temperature and moisture content expressed generally as a function describing the yield surface

$$
F\left(\sigma, f_{v}, T, w\right)=0
$$

where $\sigma$ is the stress tensor and the other terms are scalar functions of porosity $f_{v}$, temperature $T$ and moisture content $w$ (Malujda and Talaśka, 2010). The structure of the yield criterion formulated in this way is created by interrelated physical quantities which have direct effect on the value of the ultimate yield force. Wood features porosity (Malujda and Talaśka, 2010), which affects its yield point. This effect has been allowed for in the formulated mathematical model by introducing the following scalar functions of porosity

$$
A=\frac{f_{v}}{1-f_{v}} \quad B=1-f_{\nu}
$$


which, while meeting the following limit conditions:

$$
\begin{aligned}
& \text { if } f_{v} \rightarrow 0, \quad A \rightarrow 0, \text { then } B \rightarrow 1 \\
& \text { if } \quad f_{v} \rightarrow 1, \quad A \rightarrow \infty, \text { then } B \rightarrow 0
\end{aligned}
$$

reduce criterion (3.2) to $\mathrm{HMH}$ criterion.

Introducing porosity functions (3.3) accorindg to equation (3.2), we obtain

$$
A\left(\sigma_{1}+\sigma_{2}\right)^{2}+\left(\sigma_{1}-\sigma_{2}\right)^{2}=B Y_{1}^{2}
$$

where $\sigma_{1}$ and $\sigma_{2}$ are the principal stresses in the orthotropic directions $(L-T)$.

In yield criterion (3.4), the complex ultimate stress-strain state is equated to the stress-strain state expressed by the non-zero main stress determined during a uniaxial compression test as a function of temperature and moisture content $Y_{1}=R_{e_{c}}^{L}$. At the critical state, this stress obtains a constant value at the strength limit of wood. The compressive yield strength has been taken as the parameter defining the critical stress of a natural polymer, i.e. the stress created by application of the ultimate force. This parameter is used as the basis for evaluating the characteristics of composite materials, such as wood, and its value depends on temperature and moisture content as well as on the direction of load application in relation to the grain.

In the first phase of pressure application to the thin layer of wood, permanent strains are produced without a significant effect of heat. Nevertheless, they are necessary in order to obtain the roller/ surface contact time sufficient to increase the temperature to approximately $120^{\circ} \mathrm{C}$ depending on the wood variety. As it has been demonstrated in the experimental research, this process takes very little time, namely ca $0.04-0.1 \mathrm{~s}$. During that time, heat penetrates into the thin layer of wood by ca 0.1-0.12 mm which is the key element of the process of improving the material properties.

Hence, the process in consideration may be divided into two stages. The first stage concerns permanent strains created upon exceeding the proportional limit and it is related to densification of the structure of wood. In the second stage, smoothing and consolidation of the structure of the heated surface layer takes place. The yield load is reduced as a result of a decreased strength of wood resulting from an increase in temperature in the processing zone.

Introducing the orthotropy coefficients $\alpha=\left(Y_{1} / Y_{2}\right)^{2}$ and $\beta=\left(Y_{1} / Y_{3}\right)^{2}$, established on the basis of experimentally determined strength of wood $Y_{1}, Y_{2}, Y_{3}$ into equation (3.4), gives the following yield criterion

$$
\sigma_{1}^{2}+\alpha \sigma_{2}^{2}-(1+\alpha-\beta) \sigma_{1} \sigma_{2}+A \sigma_{1}^{2}+A \sigma_{2}^{2} \alpha+2 A(1+\alpha-\beta) \sigma_{1} \sigma_{2}=B Y_{1}
$$

which is then rearranged to

$$
\sigma_{1}^{2}(1+A)+\alpha \sigma_{2}^{2}(1+A)-(1-2 A)(1+\alpha-\beta) \sigma_{1} \sigma_{2}=B Y_{1}
$$

Some additional assumptions have been taken and simplifications have been made due to complexity of the process of hot rolling of wood. This process concerns plasticization of a thin layer of the processed material in the case when two dimensions are much higher than the third one. The depth of this layer $h$ is small (Fig. 11) as compared to the lateral dimensions and hence the process is analysed in the in-plane strain state. The high value of the width do depth ratio of $l / h>10$ and porosity of the material structure allow us to consider the strain in the tangential direction $T^{(2)}$ ignorable $\left(d \varepsilon_{22}=0\right)$ (Bednarski, 1995). This is supported by the approach used in real-life industrial applications. The second of the important simplifications is leaving out the stress $\sigma_{1}$ justified by the low value of the rolling resistance (ca $2 \%$ of the normal force) in the rolling direction $L^{(1)}$ (Bednarski, 1995). This is due to a very small contact angle (large diameter of the roller is required for process-related reasons) and hence it is justified to assume that the 
roller pressure $p=F /(s l)$ (Fig. 11) is almost entirely directed on the component perpendicular to the plane $L^{(1)}-T^{(2)}$ (Fig. 11).

In the next step of building up the model, we shall use the associated plastic flow rule which relates the strain increase deviator $d \varepsilon_{i j}$ to the plastic potential function $F\left(\sigma_{i j}\right)$ represented by the following relationship

$$
d \varepsilon_{i j}=d \varsigma \frac{\partial F\left(\sigma_{i j}\right)}{\partial \sigma_{i j}}
$$

where $\varsigma$ is a coefficient determined from the increase of work of plastic strain.

Hence, with the assumed value of $d \varepsilon_{i j}=0$, the associated plastic flow rule is expressed by the following formula

$$
d \varepsilon_{22}=d \varsigma \frac{\partial F}{\partial \sigma_{22}}=0
$$

Differentiating equation (3.5)

$$
\frac{\partial F}{\partial \sigma_{2}}=2 \alpha \sigma_{2}(1+A)-(1-2 A)(1+\alpha-\beta) \sigma_{1}=0
$$

yields

$$
\sigma_{2}=\frac{(1-2 A)(1+\alpha-\beta)}{2 \alpha(1+A)} \sigma_{1}
$$

Substituting expression (3.10) described by equation (3.6) to get rid of $\sigma_{2}$, we get

$$
\begin{aligned}
& \sigma_{1}^{2}(1+A)+\alpha(1+A)\left[\frac{(1-2 A)(1+\alpha=\beta)}{2 \alpha(1+A)}\right]^{2} \sigma_{1}^{2} \\
& \quad-(1-2 A)(1+\alpha-\beta) \frac{(1-2 A)(1+\alpha-\beta)}{2 \alpha(1+A)}=B Y_{1}^{2}
\end{aligned}
$$

Rearranging equation (3.11), we get the following relationship for calculating the stress $\sigma_{1}$

$$
\sigma_{1}^{2}=\frac{B}{(1+A)-\frac{(1-2 A)^{2}(1+\alpha-\beta)}{4 \alpha(1+A)}} Y_{1}^{2}
$$

Now let us use yield criterion (3.6) in order to determine the isotropic state stress

$$
A p^{2}+A \alpha p^{2}+2 A(1+\alpha-\beta) p^{2}+\beta p^{2}=B Y_{1}^{2}
$$

and thus, upon rearranging equation (3.13), we obtain

$$
p^{2}=\frac{B}{A(3+3 \alpha-2 \beta)+\beta} Y_{1}^{2}
$$

If $A \rightarrow 0$ then $p \rightarrow \infty$, where $f_{v} \rightarrow 0$ means incompressibility of the analysed material.

Finally, we get the following equation describing the yield criterion, expressing the ultimate stress state derived through transition from the in-plane strain state to the equivalent in-plane stress state

$$
p=\sqrt{\left[\frac{B}{(1+A)-\frac{(1-2 A)^{2}(1+\alpha-\beta)}{4 \alpha(1+A)}}-\frac{B}{A(3+3 \alpha-2 \beta)+\beta}\right] Y_{1}^{2}}
$$

The above expression, describing the ultimate roller pressure applied to the processed layer of wood allows for the porosity and anisotropic properties of the analysed material. Experimental determination of the compressive yield strength in the longitudinal direction $Y_{1}=R_{e_{c}}^{L}$ takes into account the effect of heat and moisture content. 


\section{Analytical and numerical solutions of the model of the thin layer plasticization process}

In the obtained analytical model, functions of material characteristics are applied including the arctangent thermal conductivity function. The relevant data are given in Table 1 . Since all the functions of material characteristics required for the determination of the critical stress according to (3.15) depend on the temperature, the values calculated with equation (3.15) are compared to the results of FEM analysis by determining the stress value for a given temperature at a given point during the rolling process modelled with the FEM software. The process parameters assumed as the input for calculations correspond to the values applied in wood improvement processes in furniture manufacturing applications. Figure 12 illustrates geometry of the model derived for the purpose of FEM analysis.

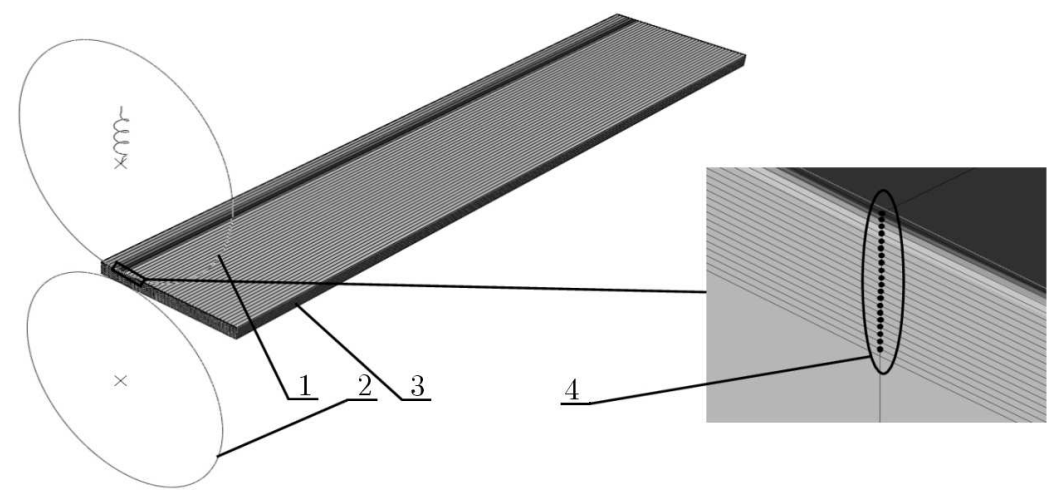

Fig. 12. Model derived for the purpose of FEM analysis: 1 - adjustable upper roller, 2 - lower roller, 3 - processed material, processed layer of wood showing nodes in the depth-wise direction

A $0.8 \mathrm{~mm}$ deep surface layer of the processed material is sub-divided into twenty finite elements. The entire model comprising of the roller and processed material is "encases" with air at temperature of $20^{\circ} \mathrm{C}$. The purpose is to imitate the real-life ambient temperature of the surrounding air which is about $20^{\circ} \mathrm{C}$. The roller/material contact parameters are defined assuming that the exchange of heat between these surfaces is close to ideal. The abutting surfaces of the roller and the processed material are assumed to have the same temperature, namely $220^{\circ} \mathrm{C}$.

The duration of contact between each point located in the thin surface whose location is defined by the co-ordinates of the node of a rectangular grid component, and the roller is assumed at ca $0.06 \mathrm{~s}$. This time corresponds to ca $6 \mathrm{~m} / \mathrm{min}$ linear speed of the roller (process parameter). The thermo-mechanical properties of beech wood and geometric parameters of the analysed wood improvement process are presented in Tables 4 and 5.

The curves in Figs. 13a,b,c represent the relation between the stress value and the depth below the surface of the rolled material determined with the use of analytically determined relationship (3.15) and FEM analysis. Figure 14 presents the relative percent difference between the values calculated with equation (3.15) and the results of FEM analysis.

\section{Conclusions}

The processes of plasticization of natural polymers in real-life conditions are governed by several parameters. The relevant factors include external mechanical loads, temperature, moisture content and process duration. Consequently, the established constitutive relations have a more general form.

The analysis of plastic strain in the analysed layer of wood is based on a generalised model of an ideally rigid-plastic medium with certain simplifications and modifications. Taking account 
Table 4. Material characteristics - thermo-mechanical properties of beech

\begin{tabular}{|c|c|c|c|}
\hline Physical quantity & Designation & Unit & Value/function \\
\hline $\begin{array}{l}\text { Arctangent thermal conducti- } \\
\text { vity in the } L, T, R \text { directions } \\
\text { in relation to the grain }\end{array}$ & $\begin{array}{l}\lambda_{\arctan }^{L} \\
\lambda_{\arctan }^{R} \\
\lambda_{\arctan }^{T}\end{array}$ & $\mathrm{~W} /\left(\mathrm{m}^{\circ} \mathrm{C}\right)$ & $\begin{array}{c}\lambda_{\arctan }^{L}=133.806 \arctan T^{2}-209.712 \\
\lambda_{\arctan }^{R}=57.723 \arctan T^{2}-90.462 \\
\lambda_{\arctan }^{T}=12.67 \arctan T^{2}-19.739\end{array}$ \\
\hline Elastic constant & $\begin{array}{l}E_{c-9 \%}^{L, R, T} \\
E_{c-1, T}^{L, R, T} \\
E_{c-27 \%}^{L, R, T}\end{array}$ & $\mathrm{MPa}$ & $\begin{array}{c}E_{c-9 \%}^{L}=-78.48 T+17809 \\
E_{c-18 \%}^{L}=-21.514 T+11574 \\
E_{c-27 \%}^{L}=-34.454 T+8530.9 \\
E_{c-9 \%}^{R}=-8.363 T+2047.2 \\
E_{c-18 \%}^{R}=-7.757 T+2022 \\
E_{c-27 \%}^{R}=-1.3884 T+1114 \\
E_{c-9 \%}^{T}=-4.0966 T+1256.5 \\
E_{c-18 \%}^{T}=-5.775 T+1278.2 \\
E_{c-27 \%}^{T}=-3.598 T+832.78\end{array}$ \\
\hline Yield strength & $\begin{array}{l}Y_{1}=R_{e_{c}}^{L} \\
Y_{2}=R_{e_{c}}^{T} \\
Y_{3}=R_{e_{c}}^{R}\end{array}$ & $\mathrm{MPa}$ & $\begin{array}{c}R_{e_{c-9 \%}}^{L}=-0.06 T+17.451 \\
R_{e_{e_{-18 \%}}}^{L}=-0.047 T+13.213 \\
R_{e_{c-27 \%}}^{L}=-0.0312 T+9.5012 \\
R_{e_{c-9 \%}}^{R}=-0.0201 T+6.0151 \\
R_{e_{c-18 \%}}^{R}=-0.014 T+4.6398 \\
R_{e_{c-27 \%}}^{R}=-0.0102 T+3.4249 \\
R_{e_{c-9 \%}}^{T}=-0.015 T+4.2452 \\
R_{e_{c-18 \%}}^{T}=-0.0128 T+3.9331 \\
R_{e_{c-27 \%}}^{T}=-0.0101 T+2.5629\end{array}$ \\
\hline $\begin{array}{l}\text { Specific heat capacity } \\
\text { of dry wood }\end{array}$ & $c_{p o}$ & $\mathrm{~kJ} /(\mathrm{kg} \mathrm{K})$ & $c_{p_{o}}=0.1031+0.003867 T$ \\
\hline $\begin{array}{l}\text { Specific heat capacity } \\
\text { allowing for the effect } \\
\text { of moisture content }\end{array}$ & $c_{p}$ & $\mathrm{~kJ} /(\operatorname{kg~K})$ & $\begin{array}{c}c_{p}=\frac{c_{p o}+0.01 w c_{p w}}{1+0.01 w+A_{k}} \\
w-\text { moisture content }(9 \%, 18 \%, 27 \%) \\
c_{p w}-\text { specific heat of water } \\
A_{k}-\text { coefficient } \\
A_{k}=-0.07592(9 \%) \\
A_{k}=-0.17338(18 \%) \\
A_{k}=-0.29238(27 \%)\end{array}$ \\
\hline Density & $\rho$ & $\mathrm{kg} / \mathrm{m}^{3}$ & 810 \\
\hline Moisture content & $m$ & $\%$ & $9,18,27$ \\
\hline
\end{tabular}

the anisotropic properties of wood, the Azzi-Tsai-Hill (ATH) strength criterion is used as it allows for the variation of reaction to the loading depending on the direction. The strength criterion is based on the experimentally determined compressive yield strength allowing for the effect of temperature and moisture content. The ultimate load determined in this way depends on the established strength criterion as well as factors defining porosity and orthotropic properties of the material which relate the yield strength values in the respective orthotropic directions. 
Table 5. Geometric parameters of the analysed wood improvement process

\begin{tabular}{|l|c|c|c|}
\hline \multicolumn{1}{|c|}{ Physical quantity } & Designation & Unit & Value \\
\hline \hline Roller radius & $R_{w}$ & $\mathrm{~m}$ & 0.1565 \\
\hline Thickness of layer before rolling & $h_{1}$ & $\mathrm{~m}$ & 0.0008 \\
\hline Linear speed & $v$ & $\mathrm{~m} / \mathrm{s}$ & 0.1 \\
\hline Roller temperature & $T$ & ${ }^{\circ} \mathrm{C}$ & 220 \\
\hline
\end{tabular}
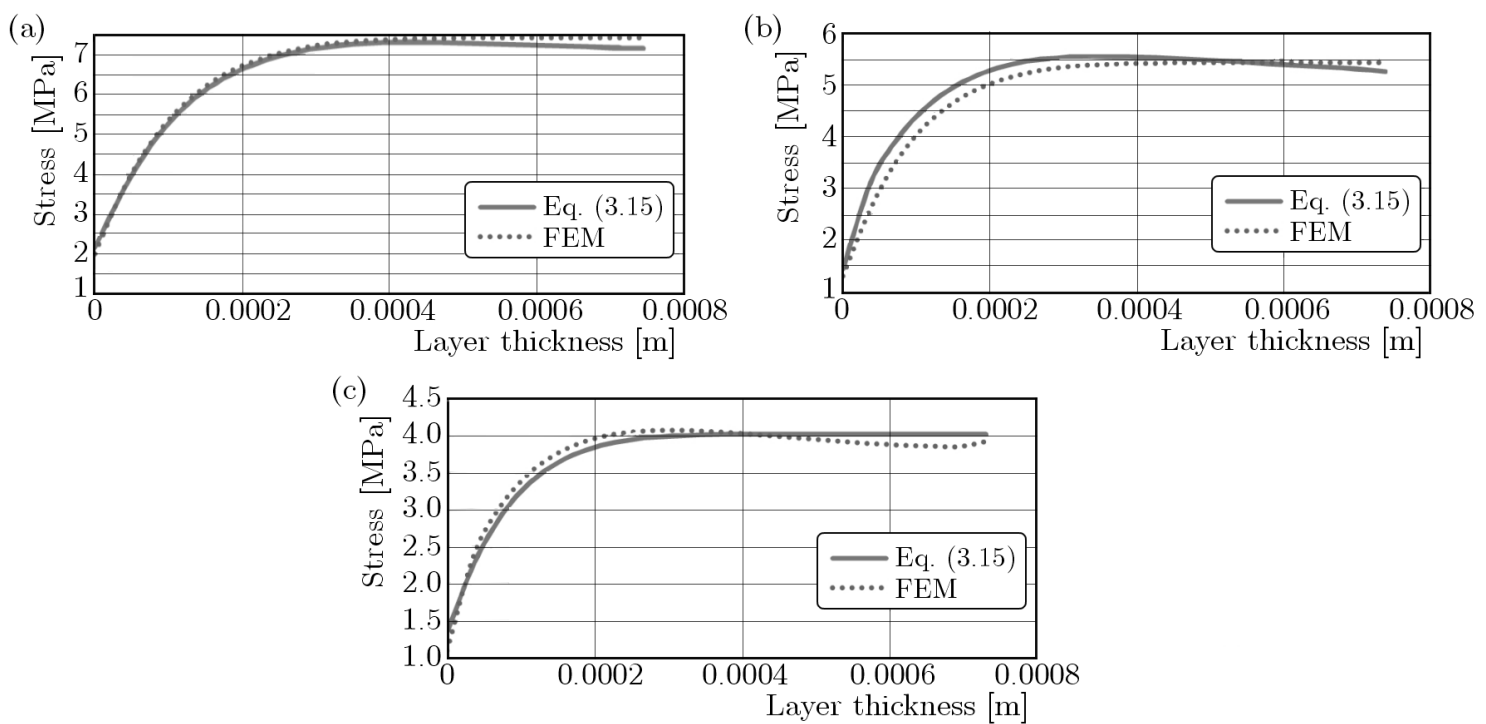

Fig. 13. Stress depending on depth inwards the processed material with (a) $9 \%$, (b) $18 \%$, (c) $27 \%$ moisture content

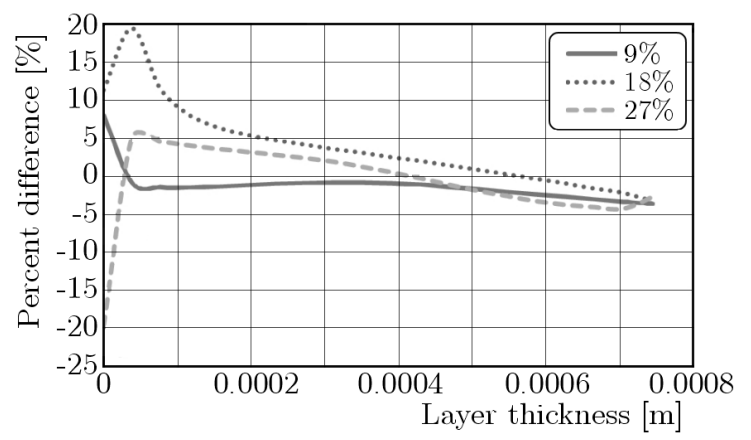

Fig. 14. Percent difference between the results of analytical and numerical calculations as a function of depth of the layer of the plasticized material

The ultimate stresses determined with the above-mentioned model are used in simulations and numerical calculations. The equations presented herein may be used to ensure the desired properties and dimensions of products and to define input assumptions and design machines used to realise the process in consideration and other similar processes.

According to the results of the process lasting ca $0.06 \mathrm{~s}$, the calculated stresses generated by the roller in the plasticized layer of wood decrease nearly two times. This is due to an increase in temperature up to the range of $110-130^{\circ} \mathrm{C}$ at which plasticization of the surface layer of wood to ca $0.1 \mathrm{~mm}$ in depth occurs.

It can be seen that an increase in the moisture content results in a decrease in the value of stress. With the moisture content of $27 \%$, the stress values are almost two times lower at the same depth. 
The percent differences between the results obtained by FEM analysis and calculated using the ultimate roller pressure formula are small. This confirms that the assumptions and simplifications made in the process of deriving constitutive relationships relating to the rolling process are appropriate.

\section{References}

1. Ashby M.F., Jones D.R.H., 1996, Engineering Materials (in Polish), WNT, Warszawa

2. Bednarski T. 1995, Mechanics of Plastic Flow at a Glance (in Polish), PWN, Warszawa 1995

3. Bordia R.K., Zuo R., Guillon O., Salamone S.M., Rodel J., 2006, Anisotropic constitutive laws for sintering bodies, Acta Materialia, 54, 111-118

4. Fujil Y., Okumura S., Inoue M., Adachi K., 2003, FE-analysis of roll pressing of wood, Proceedings of 16th International Wood Maschining Seminar, Matsue, Japan, 410-413

5. Forest Products Laboratory, 1999, Wood as an engineering material, Gen. Tech. Rep. FPL-GTR-113, Madison, WI: U.S. Department of Agriculture, Forest Service

6. German J., 2001, Fundamentals of Mechanics of Fiber Composites (in Polish), Publishing House of Cracow University of Technology, Kraków

7. Gu H.M., Zink-Sharp A., 2005, Geometric model for softwood transverse thermal conductivity. Part I, Wood and Fiber Science, 37, 4, 699-711

8. Harada, T., Hata, T., Ishinara Sh. 1998, Thermal constants of wood during the heating process measured with the laser flash method, Journal of Wood Science, 44, 425-431

9. Hill R., 1956, The Mathematical Theory of Plasticity, Clarendon Press, Oxford

10. Kokociński W., 2004, Wood: Measurement of Physical and Mechanical Properties, Poznań

11. Mackenzie-Helnwein P., Eberhardsteiner J., Mang H.A., 2005, Rate-independent mechanical behavior of biaxially stressed wood: experimental observations and constitutive modelling as an orthotropic two-surface elasto-plastic material, Holzforschung, 59, 3, 311-321

12. Malujda I., 2006, Plasticization of a bounded layer of anisotropic and loose material, Machine Dynamics Problems, 30, 4, 48-59

13. Malujda I., Marlewski A., 2011, On the heat conduction in natural porous and anisotropic materials, Proceedings of World Congress on Engineering WCE, London, Vol. I, 261-265, 37-39, Hung To Road, Hong Kong, IAENG International Association of Engineering, ISBN: 978-98818210-6-5, ISSN: 2078- 0958

14. Malujda I., TAlaśKa K., 2010, Modeling of yielding processes in porous and anisotropic natural materials, Machine Dynamics Research, 34, 4, 40-50

15. Müllner H.W., Mackenzie-Helnwein P., Eberhardsteiner J., 2004, Constitutive modelling of biaxially stressed wood for the analysis of layered wooden shells, Proceedings of 3rd International Conference of the Europe Society for Wood Mechanics, 277-284

16. NAIRN J.A., 2005, Numerical simulations of transverse compression and densification in wood, Material Science and Engineering, University of Utah, Salt Lake City, Utah

17. Sumelka W., Łodygowski T., 2013, Reduction of the number of material parameters by ANN approximation, Computational Mechanics, 52, 2, 287-300

18. Tsai S.W., Wu E.M., 1971, A general theory of strength for anisotropic materials, Journal of Composite Materials, 5, 58-80

19. YANG Q.X., 2001, Theoretical expressions of thermal conductivity of wood, Journal of Forestry Research, 12, I, 43-46 